This is an Accepted Manuscript of an article published by Taylor \& Francis in Journal of Transportation Safety \& Security on 05 Nov 2015, available online: http://www.tandfonline.com/doi/full/10.1080/19439962.2015.1046620.

\title{
Gaze direction and driving behavior of drivers at level crossings
}

\author{
Jan Grippenkoven \\ German Aerospace Center (DLR) \\ Institute of Transportation Systems \\ Braunschweig, Germany \\ Jan.Grippenkoven@DLR.de \\ (Tel.:) +49 (0)5312953507 \\ (Fax) +49 (0)531 2953402
}

\author{
Sandra Dietsch \\ German Aerospace Center (DLR) \\ Institute of Transportation Systems \\ Braunschweig, Germany
}

\begin{abstract}
International level crossing statistics reveal that the majority of accidents at level crossings occur due to human error on the part of car drivers. Often, the rather unspecific description of "attentional deficits" is given as the cause of most accidents. In this study, driving data and eye-tracking data were collected during a standardized driving study. Using a research vehicle, the behavior of 24 participants was observed while approaching two level crossings (one with passive protection, the other with active light-signal protection). It turned out that on the last $300 \mathrm{~m}$ of the approach towards level crossings, all of the drivers detected and fixated upon at least parts of the protection layout at both level crossings. Nevertheless, only one third of all participants subsequently derived the right reaction and checked the rails for an oncoming train. Two thirds of the participants did not direct their attention towards the rail tracks. With such deficient gaze behavior, visual detection of a potentially oncoming train is difficult. In addition to the maladaptive gaze patterns, inattentive drivers decelerated significantly less while approaching both level crossings than attentive drivers.
\end{abstract}

Keywords: Level crossing, driver behavior, eye tracking, attention, safety 
This is an Accepted Manuscript of an article published by Taylor \& Francis in Journal of Transportation Safety \& Security on 05 Nov 2015, available online: http://www.tandfonline.com/doi/full/10.1080/19439962.2015.1046620.

\section{Introduction}

National laws on level crossings usually contain a paragraph that states that railway level crossings should consistently be designed in a way that makes the priority of the rail transport over road traffic clearly visible (e.g. DB Netz AG, 2002). To fulfill this requirement, level crossings are equipped with different combinations of roadside signs, sometimes with additional technical systems like light signals and/or barriers, to emphasize the priority of crossing trains over road traffic users. Despite special signs and signals, road users do not always respect the train's right of way. Accidents at level crossings remain an ongoing international issue. Even though collisions at level crossings only account for a fraction of the total number of road traffic accidents, these accidents are particularly relevant because of the severe injuries and property damage they cause. Most level crossing accidents involve a motorized road user who collides with a train. 95\% of all collisions between road users and rail vehicles in Germany originate from the misconduct of a road user (DB Netz AG, 2012). The accidents are often blamed on “inattentive driving behavior" on the part of the road user or a "lack of knowledge" about rules and regulations concerning level crossings and driving characteristics of trains. Since this description of the human error is rather unspecific and often not verified, it appears necessary to put more effort into the analysis of human information processing during the approach towards level crossings. Research on this subject has been conducted by Rudin-Brown, French-St. George 
This is an Accepted Manuscript of an article published by Taylor \& Francis in Journal of Transportation Safety \& Security on 05 Nov 2015, available online: http://www.tandfonline.com/doi/full/10.1080/19439962.2015.1046620.

and Stuart (2014), who describe human factors that can lead to unsafe situations at rural level crossings. On a general level, perception (detection of a train) and cognition (understanding the need to stop) are distinguished as central factors in the task of using a level crossing. Underlying factors that were identified as having an influence on perception at level crossings were sightlines, train conspicuity, the unchanged retinal image of an approaching train (making detection difficult and leading to an underestimation of the train's speed) and difficulties with the train horn audibility. Underlying factors related to the driver's decision making were the socalled "looked-but-failed-to-see error", the faulty activation of correct schemas and mental models connected to appropriate behavior at a level crossing, distraction, driver impairment and information processing. The "looked-but-failed-to-see error" describes a situation in which drivers fail to identify hazards despite looking at the hazard's source, due to limitations in human information processing. The factor "faulty activation of schemas" is characterized by learned misbehavior and maladaptive expectations, resulting from the infrequent occurrence of a train at many level crossings.

A lot of psychological models exist that appear suitable to integrate human-factor issues that lead to unsafe conditions at level crossings, like the ones described by Rudin-Brown, French-St. George and Stuart (2014) in terms of human information processing (e.g. Broadbent, 1957, Kahneman, 1973, Wickens \& Hollands, 1999). In their model of information processing, Wickens and Hollands (1999) describe a sequence of steps, starting with early sensory perception 
This is an Accepted Manuscript of an article published by Taylor \& Francis in Journal of Transportation Safety \& Security on 05 Nov 2015, available online: http://www.tandfonline.com/doi/full/10.1080/19439962.2015.1046620.

and progressing to higher cognitive processing, that are passed before an action can be initiated. This model can be adapted to a road user’s approach towards a level crossing (figure 1).

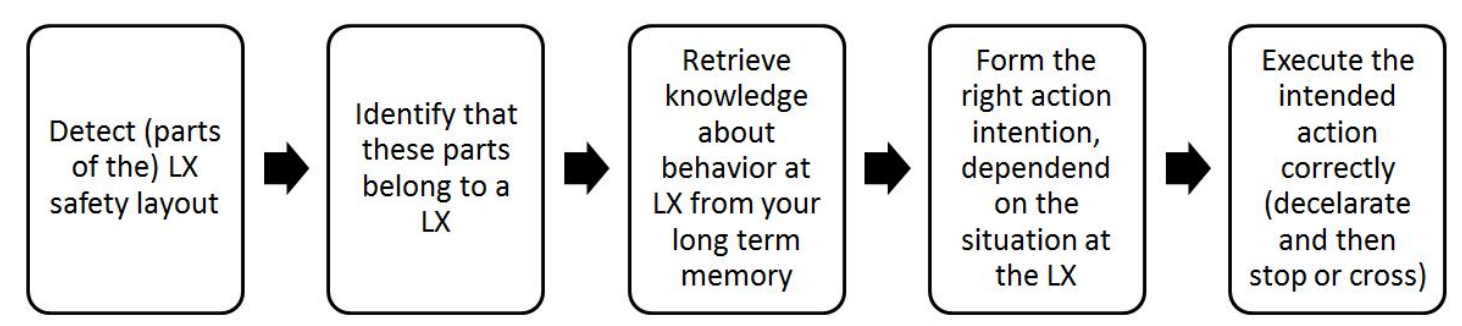

Figure 1: Necessary cognitive steps for passing a level crossing (LX)

First, drivers have to detect at least some parts of the safety layout of a level crossing (e.g. signs). Second, they have to identify these parts correctly as referring to a level crossing. Third, once identified, schemas and scripts connected to passing a level crossing have to be retrieved from the long-term memory. Fourth, an action intention, matching the current situation at the level crossing, has to be formed, based on the knowledge retrieved earlier. Fifth, the driver has to execute the intended action. In the case of the (especially passive) level crossing this means that he has to reduce the speed of the vehicle in order to listen and visually check the rails for oncoming trains and to stop if necessary. The amount of attention that the driver can invest in the task of crossing the level crossing influences information processing in each single step and can be reduced by distractions in the environment.

In several studies, aspects of driving behavior and attention during the approach towards level crossings have been investigated in different settings and countries ( $\AA$ berg, 1988, RudinBrown, Lenné, Edquist, \& Navarro 2012, Wigglesworth, 1978). Wigglesworth (1978) observed 
This is an Accepted Manuscript of an article published by Taylor \& Francis in Journal of Transportation Safety \& Security on 05 Nov 2015, available online: http://www.tandfonline.com/doi/full/10.1080/19439962.2015.1046620.

driver's behavior at level crossings in Australia with a focus on head movements that served as an indicator of the quality of the search for a potentially oncoming train during the approach towards a level crossing. Two observers surveyed driver's head movements at 14 passive and six active level crossings. All active level crossings were equipped with flashing lights. The results reveal that a majority of drivers did not search and look for a train. Especially in the case of level crossings with flashing lights, $72 \%$ of the drivers (375 out of 522 drivers) paid attention to neither the tracks to the left nor the tracks to the right. At passive level crossings, $40 \%$ of the observed drivers (181 out of 451 drivers) did not show any head movements. With a comparable method, Åberg (1988) observed a total of 584 drivers at 16 different level crossings in Sweden. 14 of these level crossings were equipped with an active protection system consisting of flashing red lights on either side of the road. The other two level crossings in Åberg's study were protected with gates. In order to evaluate the gaze direction of drivers, two observers monitored the head movements of drivers, one on each side of the highway leading towards the level crossing. Of the 584 drivers, 145 drivers (24.8\%) checked both sides of the level crossing for an oncoming train, whereas 394 (59.8\%) showed no head movements to either side. 90 drivers (15.4\%) looked at the rails to the left or right at the level crossing, but did not search for a train on either side.

Rudin-Brown, Lenné, Edquist, \& Navarro (2012) analyzed the driving behavior and the subjective perception of 25 participants during their approach towards three different Australian level crossings in a driving simulator setup. One of the simulated level crossings was protected with flashing lights and half barriers, one was equipped with traffic lights only and one had 
This is an Accepted Manuscript of an article published by Taylor \& Francis in Journal of Transportation Safety \& Security on 05 Nov 2015, available online: http://www.tandfonline.com/doi/full/10.1080/19439962.2015.1046620.

passive protection including the St Andrew's cross and stop signs. Amongst other measures, the driving performance and attention of the drivers was analyzed by comparing the number of violations at the three level crossings, reviewing the speed profiles and evaluating visual scanning patterns of drivers. A behavior was classified as a violation whenever the minimum speed of the vehicle in the simulation exceeded $10 \mathrm{~km} / \mathrm{h}$ in front of a level crossing. 14 out of 25 participants committed a violation in the case of the passive protection with stop sign, seven in the case of the half-barrier-protected level crossing and five violations were recorded in the case of the level crossing with light signals. Speed profiles of the last $280 \mathrm{~m}$ of the approach towards each level crossing were compared for the drivers that did not commit a violation. A significant difference in the speed profile was found between the level crossing with flashing lights and half barriers and the passive level crossing with stop signs. Another significant difference in the speed profile was found between the level crossing with light signals and the level crossing with stop signs. Speed profile results show that, compared to the two other level crossings, drivers slowed down earlier on approach towards the level crossing with stop signs. In addition to the driving data, visual scanning patterns of the participants were recorded. No significant difference could be found in the time spent looking at the central regions compared to the peripheral regions of the visual scene on approach to the three level crossings. These findings are in conflict with the findings of Wigglesworth (1978), who reported a different proportion of drivers that direct their attention to peripheral locations when comparing passive level crossings to active level crossings with flashing light signals. This could be due to the relatively small sample size used by RudinBrown, Lenné, Edquist, \& Navarro (2012). 
This is an Accepted Manuscript of an article published by Taylor \& Francis in Journal of Transportation Safety \& Security on 05 Nov 2015, available online: http://www.tandfonline.com/doi/full/10.1080/19439962.2015.1046620.

As a perspective for further research, Wigglesworth (1978) formulated two hypotheses concerning inadequate behavior of drivers in his sample. A possible explanation for the absence of adequate searching behavior could be that drivers are not aware of the existence of a level crossing because they fail to perceive it or the signs announcing it. An alternative explanation could be that drivers manage to detect the level crossing, but subsequently form wrong expectations because of faulty mental models or a lack of knowledge about level crossings in general.

This paper reports on an eye-tracking study that was designed to test these explanations with drivers who approach two different level crossings in a field study. It was evaluated whether drivers pay visual attention to signs and signals and subsequently derive the appropriate behavioral patterns: to reduce speed and to check whether a train is approaching. The use of eye tracking in this field study allows a more detailed analysis of driver's gaze characteristics compared to observations of head movements from outside the vehicle. It was possible to obtain precise data about every part of the environment that people were observing during the entire phase of approaching a level crossing. In addition to the eye-tracking data, speeds were recorded during the entire approach in order to be able to draw conclusions about the connection between the driver's perceptual processes and their braking behavior.

In the following section, the most common layouts of level crossing protection will be presented, followed by the methodology of the study. Afterwards, the main results concerning the 
This is an Accepted Manuscript of an article published by Taylor \& Francis in Journal of Transportation Safety \& Security on 05 Nov 2015, available online: http://www.tandfonline.com/doi/full/10.1080/19439962.2015.1046620.

eye-tracking and driving data will be presented. Finally, the implications of the results are discussed.

\section{Level crossing layout in Germany}

If you compare the safety layout of level crossings in different countries, it becomes apparent that they have a lot of characteristics in common. Nevertheless, there are some differences in the safety layout between different countries. Since the study described in this article was conducted in Germany, a short overview of the most common protective elements that are used at German level crossings is provided in table 1.

\begin{tabular}{lll}
\hline $\begin{array}{l}\text { Distance in } \\
\text { front of the }\end{array}$ & $\begin{array}{l}\text { Signs and technical } \\
\text { elements }\end{array}$ & Description \\
level crossing &
\end{tabular}

240 meters

Either sign 150 (left), announcing a level crossing in general or sign 151 , announcing a level crossing with barriers is set up. (In the future only sign 151 will be used.)

Sign 153, depicting $240 \mathrm{~m}$ distance to the

240 meters

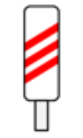

160 meters

80 meters
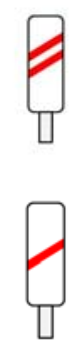
level crossing. Either sign 150 or sign 151 is installed above it. It should be located on both sides of the road.

Sign 159, depicting $160 \mathrm{~m}$ left to the level crossing. It should be located on both sides of the road.

Sign 162, depicting 80m left to the level crossing. It should be located on both sides of the road. 
This is an Accepted Manuscript of an article published by Taylor \& Francis in Journal of Transportation Safety \& Security on 05 Nov 2015, available online: http://www.tandfonline.com/doi/full/10.1080/19439962.2015.1046620.

In the immediate vicinity of the level crossing

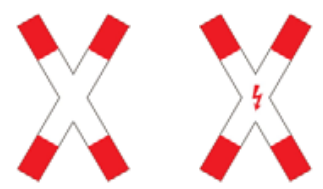

In the immediate vicinity of the level crossing

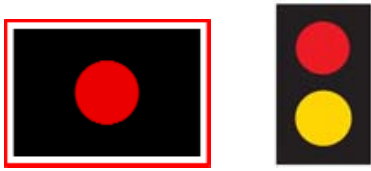

In the immediate vicinity of the level crossing

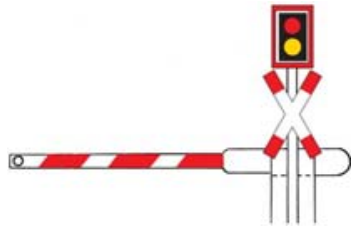

In the immediate vicinity of the level crossing
Sign 201, the “St Andrew’s Cross”, signaling the right of way of the railway traffic. It should be located on both sides of the road.

Flashing red light signal (not built anymore) and yellow-red permanent light signal. When these light signals are active the road traffic has to stop until they are turned off.

Half barrier, closing the driving lane, usually combined with a yellow-red light signal. Implemented on both sides of the rail.

Full barriers, closing the entire width of the road. Can be combined with a light signal.

Table 1: Protective elements at German level crossings (Giesa \& Bald, 2003; Grippenkoven, Giesemann \& Dietsch, 2012)

\section{METHODS}

In this study, 24 participants (9 females, 15 males) drove a predetermined route through the German city of Braunschweig in a car that was especially equipped for research purposes. The average age of the participants in the sample was 24.88 years ( $\mathrm{SD}=4.23$ years). On average, participants had held their driver's license for seven years (range: 2 to 15 years; SD = 3.31 years). Out of the original sample of 35 participants, eleven participants had to be excluded from the analysis because of technical issues that led to poor data quality or because of heavy traffic in the 
This is an Accepted Manuscript of an article published by Taylor \& Francis in Journal of Transportation Safety \& Security on 05 Nov 2015, available online: http://www.tandfonline.com/doi/full/10.1080/19439962.2015.1046620.

area of the target level crossings. Before the ride, all participants were instructed and the eyetracking system was calibrated. This procedure took between ten and 15 minutes. The ride itself took approximately 40 minutes. During the ride each participant passed two railroad level crossings. The first of these level crossings was a level crossing with passive protection (table 1: signs 151, 153, 159, 162 \& 201). The second one was an active level crossing with a yellow-red light signal system (without barriers). Both level crossings were located in a comparable, suburban environment. The driving time between both level crossings was approximately ten minutes. The maximum speed allowed on the roads leading towards both level crossings was 50 $\mathrm{km} / \mathrm{h}$ (= $31.07 \mathrm{mph})$. An experimenter was present in the back seat of the test vehicle during the entire ride. In order to be able to compare the results across all participants and rule out disturbing influences, the study was highly standardized. As part of the standardization, participants who followed another car that was driving in front of them on the last 400 meters (437.4 yards) in front of the level crossing were not included in the data analysis as well as participants that were followed by another car driving closely behind them. This strict exclusion was necessary because drivers' attention and behavior is influenced by other road users. Drivers tend to link their behavior to the car that they are following (van der Horst \& Wilmink, 1986). In order to avoid confounding the results with participants that relate their behavior to drivers in front of them or behind them, data were only included in the analysis for participants that approached the level crossing without traffic on either lane. Since the aim of the study was to obtain insights into drivers' natural behavior around level crossings, a cover story was used. Participants were told that the study was an explorative study about their usual driving behavior 
This is an Accepted Manuscript of an article published by Taylor \& Francis in Journal of Transportation Safety \& Security on 05 Nov 2015, available online: http://www.tandfonline.com/doi/full/10.1080/19439962.2015.1046620.

in normal road traffic. Participants had to be unaware of the fact that the study was actually about level crossings because their visual attention and driving behavior would otherwise have been biased. In order to avoid a situation in which the drivers' expectations influence their attention and driving behavior, it was ensured that no participant knew the level crossings that were passed during the study. To control for that, only participants that did not live near the level crossings were selected to participate in the study. After the ride, participants also had to fill in a survey with pictures of level crossings (including the level crossings that they crossed during the ride before). They had to indicate whether they knew the level crossings on the pictures before the experiment. None of the participants were familiar with the two target level crossings in the experiment.

Eye-tracking data were recorded to obtain a comprehensive overview of participants' visual perception. The eye-tracking technique allows for continuous reconstruction of the specific location in the environment the driver is looking at in each moment during the entire ride. The duration of a visual fixation can serve as an indicator of the duration of mental processing of an object in the driving environment. In this study a head-mounted eye tracker from the manufacturer SMI was used. This eye-tracking system consists of small cameras built into comfortable glasses which are directed to the eyes of the participant. A high-resolution camera films the visual field in the driving environment. The eye tracker looks and feels like ordinary glasses when worn and does not restrict the driver’s normal visual field. 
This is an Accepted Manuscript of an article published by Taylor \& Francis in Journal of Transportation Safety \& Security on 05 Nov 2015, available online: http://www.tandfonline.com/doi/full/10.1080/19439962.2015.1046620.

Driving data were recorded with an onboard recording unit in the experimental vehicle that allows analysis of the deceleration in front of the two level crossings. In order to be able to determine the speed at an exact position in the analysis afterwards, the GPS position of the car was continuously traced. After finishing the ride, all participants had to complete a short questionnaire that examined their knowledge about level crossings. Afterwards people were debriefed about the real purpose of the study and financially rewarded for their participation with $20 €$.

\section{Results}

In this section, the results of the eye-tracking data will be reported first. Then the results from the driving data will be presented. The recorded set of eye-tracking data was analyzed for a defined interval. This interval ranged from the point at which the first sign of the level crossing safety layout could be seen until the participants crossed the rails. In the introduction of this paper, we cited two explanations from Wigglesworth (1978) which he assumed to account for drivers not engaging in the search for a train at level crossings. The first was drivers' unawareness of the existence of the level crossing that can be caused by overlooking signs that announce the level crossing. The second explanation was that people have false expectations about level crossings or retrieve faulty mental models from their long-term memory. The eyetracking data for the relevant interval of the approach towards the level crossing in the current experiment was systematically reviewed in order to examine the correctness of Wigglesworth's (1978) two explanations. 
This is an Accepted Manuscript of an article published by Taylor \& Francis in Journal of Transportation Safety \& Security on 05 Nov 2015, available online: http://www.tandfonline.com/doi/full/10.1080/19439962.2015.1046620.

The first hypothesis was that drivers are not aware of the existence of a level crossing because they fail to perceive it or the signs announcing it. Explorative checks were made as to whether the participants in the sample generally perceive (parts of) the protective layout at both level crossings or not and how long elements are fixated upon. The criterion for a fixation to be counted was a visual focus on an area of interest that lasted longer than $120 \mathrm{~ms}$. This is slightly longer than the minimum fixation duration of $100 \mathrm{~ms}$ that is recommended for eye-tracking research in the automotive context by Seifert, Rötting \& Jung (2001).

In the case of the passive level crossing, an average of $15 \%$ of the total fixation time during the approach was spent fixating upon level-crossing-related signs. For the active level crossing including the yellow-red light signaling system, the fixations on signs and signals accounted for $19.9 \%$ of the total fixation time. For both level crossings, all of the participants in the sample visually fixated upon at least some of the signs. A detailed overview of the average percentage of the total fixation times for the relevant signs during approach towards the level crossings is given in table 2. The hypothesis was tested as to whether the presence of a light signal leads to a difference in the total fixation duration for the level crossings signs in comparison to a passive level crossing $\left(\mathrm{H}_{0}\right.$ : There is no difference in fixation duration; $\mathrm{H}_{\mathrm{A}}$ : There is a difference in fixation duration). Comparing the total fixation duration on the signs at the two level crossings that were crossed in the study with a paired-samples t-test, no significant statistical difference could be found for the tested sample $\left(\mathrm{t}=1.13\right.$, $\mathrm{df}=23, \mathrm{p}=0.27 ; \mathrm{H}_{\mathrm{A}}$ has to be rejected in favor of $\left.\mathrm{H}_{0}\right)$. 
This is an Accepted Manuscript of an article published by Taylor \& Francis in Journal of Transportation Safety \& Security on 05 Nov 2015, available online: http://www.tandfonline.com/doi/full/10.1080/19439962.2015.1046620.

\begin{tabular}{|c|c|c|c|c|}
\hline & \multicolumn{2}{|c|}{$\begin{array}{l}\text { Average percentage of total } \\
\text { fixation } \\
\text { duration during approach }\end{array}$} & \multicolumn{2}{|c|}{$\begin{array}{l}\text { Number of persons that showed } \\
\text { at least one fixation }\end{array}$} \\
\hline & $\begin{array}{l}\text { Passive } \\
\text { level crossing }\end{array}$ & $\begin{array}{l}\text { Active level } \\
\text { crossing } \\
\text { with light signal }\end{array}$ & $\begin{array}{l}\text { Passive } \\
\text { level crossing }\end{array}$ & $\begin{array}{l}\text { Active level } \\
\text { crossing } \\
\text { with light signal }\end{array}$ \\
\hline Train sign at $240 \mathrm{~m}$ & $3.6 \%$ & $0.9 \%$ & 18 & 9 \\
\hline St Andrew's cross & $1.7 \%$ & $2.3 \%$ & 16 & 13 \\
\hline Light signal & --- & $5.6 \%$ & --- & 19 \\
\hline $\begin{array}{l}\text { Other level crossing } \\
\text { related signs }\end{array}$ & $9.7 \%$ & $11.1 \%$ & 24 & 24 \\
\hline $\begin{array}{l}\text { Road and } \\
\text { environment }\end{array}$ & $85 \%$ & $80.1 \%$ & 24 & 24 \\
\hline
\end{tabular}

Table 2: Visual fixation of relevant elements at the level crossings in the study

Wigglesworth’s (1978) second hypothesis was that drivers detect the level crossing, but form false expectations because of faulty mental models about level crossings or a lack of knowledge. Since all of the participants in the sample displayed fixations on signs announcing the level crossings, the next step during the approach towards the level crossing (given correct scripts and mental models) would be to search for a train that could be approaching from the left or right. Based on the findings by Wigglesworth (1978), it was assumed that in the case of the active level crossing, fewer people would search for an oncoming train compared to the passive level crossing because of a high level of trust in the light signals as a sufficient source of information. The eyetracking data were analyzed for the searching behavior for a potentially oncoming train in front of the level crossing. In the cases of both level crossings that were crossed in the experiment, a similarly high number of participants did not check for a train that could be approaching (passive level crossing: 16 out of 24; active level crossing: 15 out of 24). In the case of the level crossing 
This is an Accepted Manuscript of an article published by Taylor \& Francis in Journal of Transportation Safety \& Security on 05 Nov 2015, available online: http://www.tandfonline.com/doi/full/10.1080/19439962.2015.1046620.

with light signals, this result can be interpreted in relation to the proportion of fixations on the light signals that provide the necessary information about an oncoming train. In the case of the passive level crossing, the insufficient searches made by two-thirds of the participants for an approaching train are more dangerous. No additional visual information exists to tell a driver whether a train is coming or not.

With regard to the driving data, it was assumed that participants would show a stronger deceleration at a passive level crossing compared to an active level crossing because of the absence of an active warning system and the resulting stronger necessity for an active search for a train. This hypothesis was tested by comparing the participant's speed on the last meter before crossing the rails of both level crossings $\left(\mathrm{H}_{0}\right.$ : There is no difference in the speed; $\mathrm{H}_{\mathrm{A}}$ : Drivers are slower in front of the passive level crossing than in front of the active level crossing). A paired sample t-test was calculated to test this hypothesis. In front of the passive level crossing, drivers slowed down to $38.6 \mathrm{~km} / \mathrm{h}$ (23.98 mph) on average. The speed was reduced to $40.2 \mathrm{~km} / \mathrm{h}$ in front of the active level crossing. This difference did not reach statistical significance $(\mathrm{t}=-.982, \mathrm{df}=$ 23, $\mathrm{p}=.336 ; \mathrm{H}_{\mathrm{A}}$ has to be rejected in favor of $\mathrm{H}_{0}$ ).

Overall driving data (table 3) reveal that the participants in the sample slightly reduced the speed of the test vehicle during the approach towards the railway crossing. The initial speed reductions usually took place around 80 to 50 meters ( 87.5 to 54.7 yds.) in front of the level crossing. At a speed limit of $50 \mathrm{~km} / \mathrm{h}$ (31.07 mph), participants reduced their speed on average to $38.6 \mathrm{~km} / \mathrm{h}$ (23.98 $\mathrm{mph}$ ) before they passed the passive level crossing. In the case of the level 
This is an Accepted Manuscript of an article published by Taylor \& Francis in Journal of Transportation Safety \& Security on 05 Nov 2015, available online: http://www.tandfonline.com/doi/full/10.1080/19439962.2015.1046620.

crossing with light signals they reduced their speed on average to $40.2 \mathrm{~km} / \mathrm{h}(24.98 \mathrm{mph})$ when they passed it.

\begin{tabular}{lccccc}
\hline Level crossing (LX) & $\begin{array}{c}\text { Maximum } \\
\text { speed allowed }\end{array}$ & $\begin{array}{c}\text { Average speed } \\
\text { just before } \\
\text { crossing }\end{array}$ & $\begin{array}{c}\text { Average speed } \\
\text { of people that } \\
\text { looked if a } \\
\text { train is coming }\end{array}$ & $\begin{array}{c}\text { Average speed } \\
\text { of people that } \\
\text { did not look if } \\
\text { a train is } \\
\text { coming }\end{array}$ \\
\hline Passive LX & $\mathrm{km} / \mathrm{h}$ & 50 & 38.6 & 33.2 & 41.9 \\
& $\mathrm{mph}$ & 31.07 & 23.98 & 20.63 & 26.04 \\
$\begin{array}{l}\text { Active LX } \\
\text { with light } \\
\text { signal }\end{array}$ & $\mathrm{km} / \mathrm{h}$ & 50 & 40.2 & 33.5 & 43.5 \\
\hline
\end{tabular}

Table 3: Driving behavior of the participants

In a post-hoc analysis, the sample was divided into two subsamples of people that checked for a train and people that did not. The participants who checked the rails for an oncoming train crossed the passive level crossing at an average speed of $33.2 \mathrm{~km} / \mathrm{h}(20.63 \mathrm{mph})$ and the level crossing with light signals at an average speed of $33.5 \mathrm{~km} / \mathrm{h}$ (20.82 mph). The speed of participants who did not check for an oncoming train was significantly higher at both level crossings. Their speed at the passive level crossing was $41.9 \mathrm{~km} / \mathrm{h}(26.04 \mathrm{mph})$ and $43.5 \mathrm{~km} / \mathrm{h}$ at the level crossing with light signals (26.75 mph). A graphical overview of the deceleration during the last $240 \mathrm{~m}$ of the approach towards both level crossings is given in figures $2+3$. An analysis of variance with repeated measures showed that the measured speed at the level crossing significantly differed between the participants who checked for a train compared to those who did 
This is an Accepted Manuscript of an article published by Taylor \& Francis in Journal of Transportation Safety \& Security on 05 Nov 2015, available online: http://www.tandfonline.com/doi/full/10.1080/19439962.2015.1046620.

not check, both for the passive level crossing $(\mathrm{F}=7.08 \mathrm{df}=1.15, \mathrm{p}<0.05)$ and for the level crossing with light signals $(\mathrm{F}=17.53, \mathrm{df}=1.67, \mathrm{p}<0.01)$.

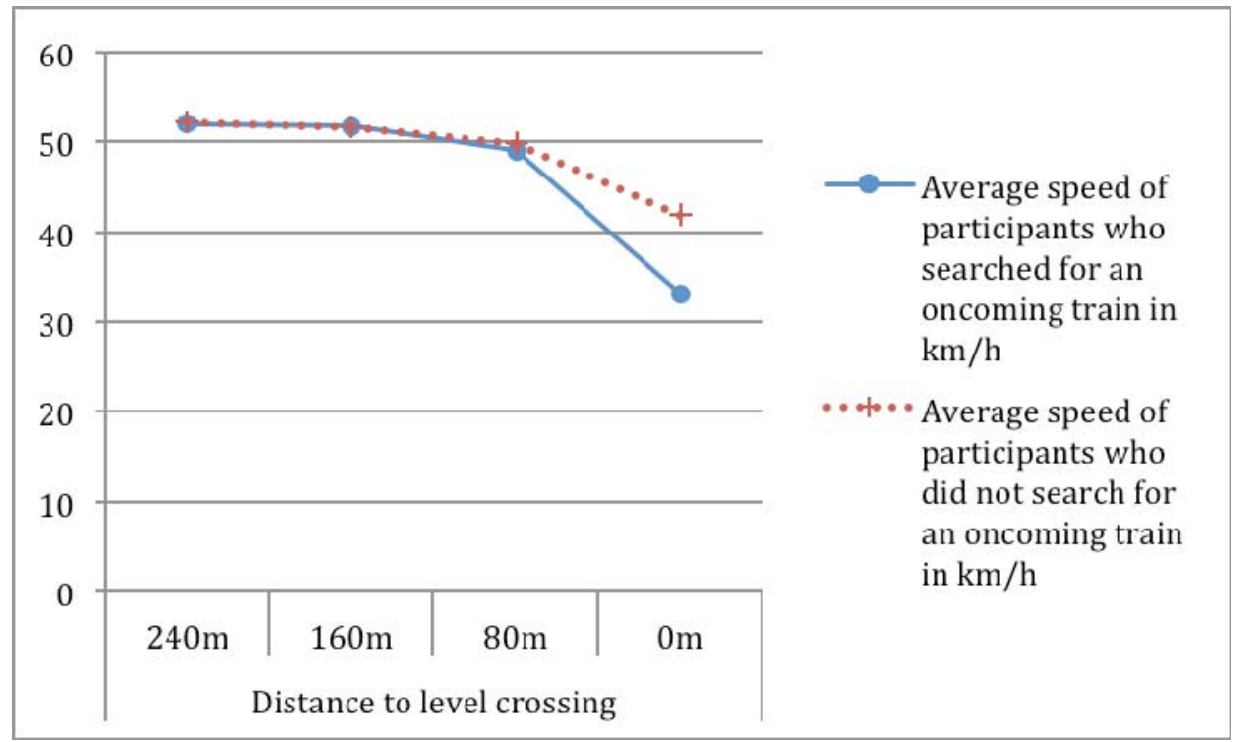

Figure 2: Deceleration of participants at the passive level crossing. 
This is an Accepted Manuscript of an article published by Taylor \& Francis in Journal of Transportation Safety \& Security on 05 Nov 2015, available online: http://www.tandfonline.com/doi/full/10.1080/19439962.2015.1046620.

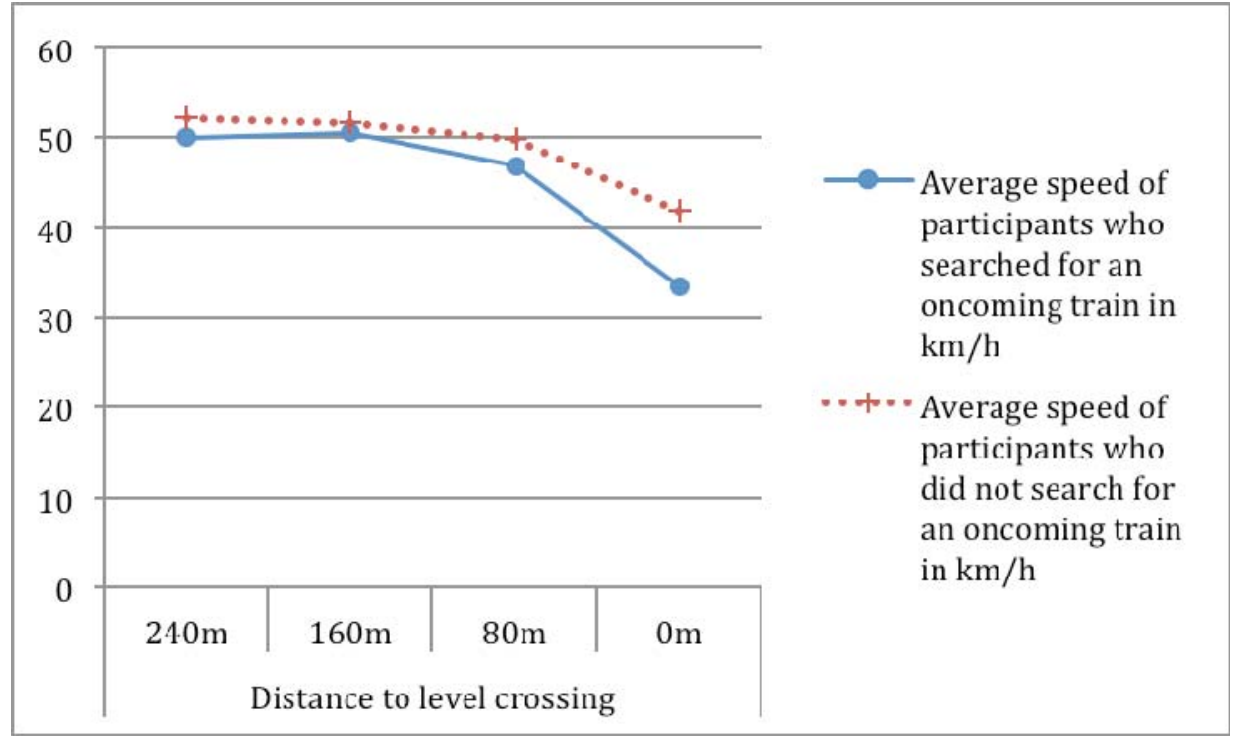

Figure 3: Deceleration of participants at the active level crossing with light signals

\section{Discussion}

The aim of the study was to describe and compare driver behavior at two different level crossings. Results based on eye-tracking data and driving data from an analysis involving 24 participants were presented. The level crossing environment requires distinct steps of information processing a driver has to run through, starting with the detection of elements that announce the level crossing via the retrieval of schemas and scripts connected to level crossings through to the formation of an action plan, like looking and listening if there is evidence of an oncoming train and stopping if necessary.

As indicated by the eye-tracking data in this study, all participants perceived at least parts of the safety layout announcing the level crossing. An average of $15 \%$ of the fixation time was spent 
This is an Accepted Manuscript of an article published by Taylor \& Francis in Journal of Transportation Safety \& Security on 05 Nov 2015, available online: http://www.tandfonline.com/doi/full/10.1080/19439962.2015.1046620.

on level crossing signs during the approach towards the passive level crossing. $19.9 \%$ of the total fixation duration was spent fixating upon signs and signals in the case of the active level crossing. Given an approach time of 20 - 25 seconds, this fixation percentage appears sufficient for a driver to notice that he is heading towards a level crossing. Nevertheless, most of the drivers in the sample did not show adequate searching behavior. Despite the fact that drivers looked at the signs, two-thirds of them subsequently did not look for an oncoming train and reduced the speed only slightly. In terms of the model of information processing (Wickens \& Hollands, 1999), it can be concluded that the problem of maladaptive behavior in the case of both level crossings is not a problem of perception or overlooking. It rather appears that many of the participants do not know how to behave when facing signs and signals that announce a level crossing because they have neither proper mental models nor scripts that can be applied when perceiving, for example, a St Andrew's cross. This conclusion is in line with the second thesis by Wigglesworth that was mentioned in the introduction of this article. However, a possible alternative explanation that should not be ruled out is that drivers could have committed a kind of looked-but-failed-to-see error (in absence of an immediate threat) as described by Rudin-Brown, French-St. George and Stuart (2014). It is possible that signs that were fixated upon were only processed in a premature sensory stage but did not reach deeper stages of processing like the identification and the retrieval of schemas and scripts connected to it.

With regard to the driving data, it should be noted that the minimal braking deceleration a car needs to be capable of in order to obtain a vehicle registration in Germany is $5.0 \mathrm{~m} / \mathrm{s}^{2}$ (Federal 
This is an Accepted Manuscript of an article published by Taylor \& Francis in Journal of Transportation Safety \& Security on 05 Nov 2015, available online: http://www.tandfonline.com/doi/full/10.1080/19439962.2015.1046620.

Ministry of Justice and Consumer Protection, 2012). If you assume a more realistic braking deceleration value between $-6.5 \mathrm{~m} / \mathrm{s}^{2}$ and $-7.5 \mathrm{~m} / \mathrm{s}^{2} \mathrm{~km} / \mathrm{h}$ for a car that is braking on a dry street and add a reaction time of one second, an overall stopping distance of $22.06 \mathrm{~m}-20.67 \mathrm{~m}$ results for a car travelling with a speed of $41.9 \mathrm{~km} / \mathrm{h}$ (as in the case of participants that did not look for an oncoming train at the passive level crossing in this study). At the passive level crossing passed during the ride in this study, a driver is able to detect a train at the earliest from a distance of $20 \mathrm{~m}$. This means that, given their average speed of $41.9 \mathrm{~km} / \mathrm{h}$, drivers in the sample that did not actively search for a train would not have been able to stop in front of the rails. Drivers that searched for a train at the passive level crossing travelled with a speed of $33.5 \mathrm{~km} / \mathrm{h}$ and would have needed an overall stopping distance of $15.76 \mathrm{~m}-15.08 \mathrm{~m}$ (given a braking deceleration of $6.5 \mathrm{~m} / \mathrm{s}^{2}$ and $-7.5 \mathrm{~m} / \mathrm{s}^{2}$ ). They would have been able to brake and stop in front of the level crossing. The insufficient speed reduction and deficient gaze patterns that were found for the two-thirds of the participants that did not search for a train could lead to dangerous situations in the case of an oncoming train. This type of behavior is a potential cause of accidents at passive level crossings.

Based on the results, it has to be questioned if people have a proper knowledge of levelcrossing-related signs, for example the meaning of the St Andrew's cross as an indicator for the train's right of way. Drivers are used to passing road intersections and looking out for cars coming from the left or right in order to draw conclusions about the right of way. The same behavioral patterns are required at a railway level crossing. Nevertheless, a majority of people do not appear to treat a level crossing like an intersection in road traffic. From this perspective it 
This is an Accepted Manuscript of an article published by Taylor \& Francis in Journal of Transportation Safety \& Security on 05 Nov 2015, available online: http://www.tandfonline.com/doi/full/10.1080/19439962.2015.1046620.

appears reasonable to allow the implementation of stop signs at level crossings in countries where they are still forbidden. Even if people do not stop, most drivers know from their experience in road traffic that a stop sign announces a dangerous crossing. Drivers would probably at least look for a potential hazard even if they do not stop in the absence of a hazard. Besides considerations about level-crossing-related signs, more emphasis has to be placed on the topic of level crossings in driving lessons. With an average age of 24.8 years, it can be assumed that many participants in the sample of this study have undergone driving lessons quite recently. However, the mental scripts that participants have acquired about the mandatory behavior at level crossings appear to have faded in many cases. Given the findings of this study, the extent to which the topic of level crossings is taught in driving schools should be reconsidered.

Additional technological measures that are capable of enhancing the driver's understanding of how to behave at level crossings should be implemented. If people are not used to slowing down and searching for a train that could be approaching at a level crossing, it could for example be useful to have a vehicle assistance system to inform drivers about what to do when approaching the level crossing (e.g. "slow down and look for a train”). Another way of enhancing safety lies in the design of the level crossing itself. If the signs and signals are not meaningful enough for drivers, a level crossing could be designed in a way that makes people engage in the correct action automatically. A boom barrier for example is a physical obstacle that can cause damage to you and your car and is easily understandable without having to realize that 
This is an Accepted Manuscript of an article published by Taylor \& Francis in Journal of Transportation Safety \& Security on 05 Nov 2015, available online: http://www.tandfonline.com/doi/full/10.1080/19439962.2015.1046620.

the barrier belongs to a railway level crossing. Of course, it would be expensive to build automatic full-barrier systems in front of every single level crossing, but there are also cheaper ways of making people automatically engage in the correct behavior at a level crossing and these should be considered to to make level crossings safer. Speed bumps or rumble strips for example are often discussed in the literature (Gates, Qin, \& Noyce, 2008; Radalj \& Kidd, 2005;

Thompson, Burris, \& Carlson, 2006) and can be helpful in making people reduce their speed. Even without knowing that they are reducing their speed for the sake of a level crossing ahead, a lower speed raises the chances of detecting a train and being able to stop in front of the level crossing. Nevertheless, rumble strips are not capable of making people directly watch out for an oncoming train. It is unlikely that a mental connection between a feeling of vibration induced by rumble strips and the need to engage in a search for a train will be formed by the driver.

Therefore, additional measures should be considered that make people automatically direct their attention to their periphery and into the direction of the tracks. Flashing lights in the periphery of the driver's visual field that are located next to the tracks could be a solution. An abrupt stimulus onset like a strobe light could draw the driver's attention to the source of the stimulus, especially in the visual periphery (Remington, Johnston, \& Yantis, 1992; Yantis \& Jonides, 1984). The idea of installing strobe lights at the front of trains to facilitate their detection for road users was reported by Caird, Creaser, Edwards and Dewar (2002) and appears reasonable in the light of findings concerning mechanisms of human attention. Strobe lights do not necessarily have to be installed on trains, they could also be located in a region around $30-50 \mathrm{~m}$ to the left and right of level crossings. These lights could be triggered for example by a light barrier sensor or ultrasonic 
This is an Accepted Manuscript of an article published by Taylor \& Francis in Journal of Transportation Safety \& Security on 05 Nov 2015, available online: http://www.tandfonline.com/doi/full/10.1080/19439962.2015.1046620.

sensor located next to the street. If a car passes the sensor, the flashing lights can be turned on in order to attract the driver's attention to the left and the right, the directions a train could come from. Further research on the topic of driver's attention at level crossings should be conducted, especially on the bottom-up approach of drawing driver's attention to areas a train could come from.

As in many field studies, there are limitations to this study that have to be mentioned. For a comparison of the attentional processes during the approach of two different level crossings, in a within-subjects design, a sample size of 24 participants appears acceptable. Still, a larger sample size with a more heterogeneous age structure would have been desirable. Results have to be treated with caution when generalizing the findings from this study to the overall driving population. Still, this study demonstrated that accidents at level crossing are not a simple problem caused by inattentive drivers. Many drivers in fact do pay attention to the safety layout at level crossings, they simply do not derive the right behavioral patterns from it. The combination of eye-tracking data and driving data in a real-world driving setting is well suited to the analysis of driver behavior at level crossings. This method is recommended for future studies with larger sample sizes that address safety measures aiming at raising the driver's level of attention around level crossings. 
This is an Accepted Manuscript of an article published by Taylor \& Francis in Journal of Transportation Safety \& Security on 05 Nov 2015, available online: http://www.tandfonline.com/doi/full/10.1080/19439962.2015.1046620.

\section{References}

Åberg, L. (1988). Driver Behavior At Flashing-Light, Rail-Highway Crossings. Accident Analysis \& Prevention, 59-65.

Broadbent, D. E. (1957). A mechanical model for human attention and immediate memory. Psychological Review, 205-215.

Caird, J. K., Creaser, J. I., Edwards, C. J., \& Dewar, R. E. (2002). A human factors analysis of highway-railway grade crossing accidents in Canada. University of Calgary. Montreal, Canada: Transport Canada Report.

DB Netz AG. (2002). Richtlinie 815: Bahnubergangsanlagen planen und Instandhalten. Frankfurt am Main: DB Netz AG.

DB Netz AG. (2012). Sicher Drüber - Infografiken. Frankfurt am Main: Deutsche Bahn AG.

Federal Ministry of Justice and Consumer Protection. (2012). StVZO § 41(4). Road Traffic Licensing Regulations. Berlin, Germany.

Gates, T. J., Qin, X., \& Noyce, D. A. (2008). Effectiveness of experimental transverse-bar pavement marking as speed-reduction treatment on freeway curves. Transportation Research Record: Journal of the Transportation Research Board, 95-103.

Grippenkoven, J., Giesemann, S., \& Dietsch, S. (2012). Contributing Human Factors in German Level-Crossing Accidents. Proceedings of the 30th European Annual Conference on Human Decision-Making and Manual Control (pp. 97-108). Braunschweig: German Aerospace Center (DLR e.V.).

Kahneman, D. (1973). Attention and Effort. Englewood Cliffs, NJ: Prentice-Hall Inc.

Radalj, T., \& Kidd, B. (2005). A trial with rumble strips as a means of alerting drivers to hazards at approaches to passively protected railway level crossings on high speed western australian rural roads. Proceedings of the Road Safety Research, Policing and Education Conference. Wellington, New Zealand.

Remington, R. W., Johnston, J. C., \& Yantis, S. (1992). Involuntary attentional capture by abrupt onsets. Perception \& Psychophysics, 279-290. 
This is an Accepted Manuscript of an article published by Taylor \& Francis in Journal of Transportation Safety \& Security on 05 Nov 2015, available online: http://www.tandfonline.com/doi/full/10.1080/19439962.2015.1046620.

Rudin-Brown, C. M., French-St. George, M., \& Stuart, J. J. (2014). Human factors issues at passively controlled, rural level crossings. Compendium of the 2015 TRB annual meeting (pp. 96-103). Washington, D.C.: Transportation Research Board.

Rudin-Brown, C. M., Lenné, M. G., Edquist, J., \& Navarro, J. (2012). Effectiveness of traffic light vs. boom barrier controls at road-rail level crossings: A simulator study. Accident Analysis \& Prevention , 187-194.

Seifert, K., Rötting, M., \& Jung, R. (2001). Registrierung von Blickbewegungen im Kraftfahrzeug. In T. Jürgensohn, \& K. P. Timpe, Kraftfahrzeugführung (S. 207-228). Berlin: Springer-Verlag.

Thompson, T. D., Burris, M. W., \& Carlson, P. J. (2006). Speed changes due to transverse rumble strips on approaches to high-speed stop-controlled intersections. Transportation Research Record: Journal of the Transportation Research Board 1973, 1-9 .

van der Horst, R., \& Wilmink, A. (1986). Drivers' decision-making at signalised intersections: an optimisation of the yellow timing. Traffic Engineering + Control, 615-622.

Wickens, C. D., \& Hollands, J. G. (1999). Engineering Psychology and Human Performance. Addison Wesley Longman.

Wigglesworth, E. C. (1978). Human factors in level crossing accidents. Accident analysis and Prevention, 229-240.

Wöllmann, M. F. (2013). Beschilderung am Bahnübergang - Aufmerksamkeit frühzeitig erhöhen. Saarbrücken: AV Akademikerverlag.

Yantis, S., \& Jonides, J. (1984). Abrupt visual onsets and selective attention: Evidence from visual search. Journal of Experimental Psychology: Human Perception \& Performance, 601-621. 